\title{
Picosecond pulsed electric fields induce apoptosis in HeLa cells via the endoplasmic reticulum stress and caspase-dependent signaling pathways
}

\author{
WEN-JUAN CHEN ${ }^{1}$, ZHENG-AI XIONG ${ }^{1}$, MIN ZHANG ${ }^{1}$, CHEN-GUO YAO $^{2}$, \\ ZHONG-YONG ZHAO ${ }^{2}$, YUAN-YUAN HUA ${ }^{1}$ and WEI ZHOU ${ }^{1}$ \\ ${ }^{1}$ Department of Obstetrics and Gynecology, The Second Affiliated Hospital of Chongqing Medical University, \\ Chongqing 400010; ${ }^{2}$ State Key Laboratory of Power Transmission Equipment and System Security \\ and New Technology, Chongqing University, Chongqing 400044, P.R. China
}

Received October 30, 2012; Accepted December 18, 2012

DOI: 10.3892/ijo.2013.1774

\begin{abstract}
The non-invasive treatment of tumors with preserved fertility holds great promise. The application of pulsed electric field (PEF) is a new biomedical engineering technique for tumor therapy. Picosecond pulsed electric fields (psPEF) can be transferred to target deep tissue non-invasively and precisely; however, research of the biological effects of psPEF on cells is limited. Electric theory predicts that when the pulse duration decreases to nanoseconds and picoseconds, it will mainly affect organelles and lead to intracellular electromanipulations. Previous studies have shown that psPEF targets the mitochondria and induces apoptosis through a mitochondrial-mediated pathway in HeLa cells. The endoplasmic reticulum is also involved in the intrinsic pathways of apoptosis. In the present study, HeLa cells were exposed to psPEF to investigate the underlying mechanisms of apoptosis. MTT assay demonstrated that psPEF displayed strong growth inhibitory effects on HeLa cells. Treatment with psPEF led to marked cell apoptosis and cell cycle arrest at the $\mathrm{G}_{2} / \mathrm{M}$ phase. In addition, psPEF affected the phosphorylation levels of endoplasmic reticulum sensors and upregulated the expression of glucose-regulated protein 78 (GRP78), glucose-regulated protein 94 (GRP94) and CCAAT enhancer-binding protein (C/EBP) homologous protein (CHOP). These changes were accompanied by the elevation of intracellular $\mathrm{Ca}^{2+}$ concentrations. Furthermore, the activation of caspase-12, -9 and -3 , led to the release of cytochrome $c$, as well as the upregulation of Bax and the downregulation of $\mathrm{Bcl}-2$, as observed in the HeLa cells. Taken together, these data
\end{abstract}

Correspondence to: Professor Zheng-Ai Xiong, Department of Obstetrics and Gynecology, The Second Affiliated Hospital of Chongqing Medical University, 74 Linjiang Road, Central District, Chongqing 400010, P.R. China

E-mail: paperxiong@126.com

Key words: picosecond pulsed electric fields, apoptosis, endoplasmic reticulum stress, caspase, HeLa cells suggest that psPEF is an efficient apoptosis-inducing agent for HeLa cells, which exerts its effects, at least partially, via the endoplasmic reticulum stress and caspase-dependent signaling pathways.

\section{Introduction}

Cervical carcinoma, the most common malignant tumor of the female reproductive system, is a serious threat to the physical and mental health of women worldwide (1). Despite advances in surgical techniques, including conservative treatments, such as radical trachelectomy, the fertility of patients is still highly affected (2). In recent years, non-invasive treatment with preserved fertility has increasingly become the expectation of doctors as well as patients.

In 1992, Okino et al (3) first originated the concept of electrochemotherapy (ECT) on the basis of electroporation. The lipid bilayer of cells is temporarily rearranged, followed by the formation of aqueous channels in the cell membrane when exposed to long pulses (millisecond to microsecond), termed electroporation, which was proposed by Weaver (4). Over the past two decades, electrochemical therapy has received a gret deal of attention and tremendous progress has been made in this field. Electrochemical therapy is based on a pulsed electric field (PEF). According to the pulse duration, PEF can be classified into millisecond (msec), microsecond ( $\mu \mathrm{sec})$, nanosecond (nsec) and picosecond (psec). Previous studies have shown that the main effect of the msec and $\mu$ sec pulses occurs in the cell membrane. PEF causes a tremendous increase in molecular transportation across the cell membrane, thus, many electroporation techniques are applied in cell transfection for gene expression and drug delivery. For example, Hofmann et al (5) and Dev et al (6) applied electricochemotherapy in conjuction with the administration of bleomycin for the treatment of tumors, which significantly reduced the side-effects of the drugs. When the pulse duration decreases to nsec and psec, it mainly affects organelles and leads to intracellular electromanipulations such as apoptosis, an intracellular calcium burst, as well as cytoskeletal, nuclear membrane and DNA damage, with the outer membrane remaining intact (7-9). 
Apoptosis, a genetically controlled mode of cell death, is of critical importance for the removal of potentially dangerous cells, including precursor tumor cells (10). It usually occurs through two major pathways. One is the extrinsic pathway, in which the ligation of death receptors by death ligands is followed by the recruitment of adaptor molecules and the activation of caspase- 8 or -10 (11). The other is the intrinsic pathway, in which pro-apoptotic signals provoke the release of cytochrome $c$ from the mitochondrial inter-membranous space into the cytosol, which forms a complex with Apaf-1, pro-caspase-9 and dATP, known as apoptosome. Apoptosome formation leads to the subsequent activation of executioner caspases, such as caspase-3, -6 and -7, which in turn stimulates a series of apoptotic events, eventually leading to cell death (12,13). A previous study suggested that the mitochondria and endoplasmic reticulum (ER) play important roles in the intrinsic pathways of apoptosis (14).

ER serves as a critical site responsible for regulating protein synthesis, protein folding and intracellular calcium $\left(\mathrm{Ca}^{2+}\right)$ homeostasis (15). The abnormalities in the ER function can cause ER stress and ultimately trigger apoptosis through a variety of mechanisms, including redox imbalance, alteration in $\mathrm{Ca}^{2+}$ levels and the activation of the Bcl-2 family of proteins (16). ER stress is mediated by three ER sensors: double-stranded RNA-activated protein kinase-like ER kinase (PERK), activating transcription factor 6 (ATF6) and inositol requiring enzyme-1 (IRE1) (17). Additionally, CCAAT enhancer-binding protein $(\mathrm{C} / \mathrm{EBP})$ homologous protein $(\mathrm{CHOP})$, a transcription factor, is believed to play an important role in promoting ER stress-induced apoptosis (18).

Our group has been dedicated to studying the antitumor effects of microsecond PEF ( $\mu \mathrm{SPEF}$ ) or nanosecond PEF (nsPEF) for a number of years. Our previous studies showed that the mitochondrial and ER stress pathways cooperate in nsPEF-induced human ovarian cancer SKOV-3 cell apoptosis (19-21). In addition, we have previously demonstrated that psPEF induces apoptosis through a mitochondrial-mediated pathway in HeLa cells (22). To determine whether psPEFinduced apoptosis in cervical carcinoma cells is mediated through the ER stress pathway, we chose the human cervical carcinoma cell line,HeLa, as an in vitro model to explore the effects of psPEF.

\section{Materials and methods}

Chemicals and reagents. RPMI-1640 medium and fetal bovine serum (FBS) were purchased from Gibco (Grand Island, NY, USA); 3-(4,5-dimethylthiazol-2-yl) 2,5-diphenyltetrazolium bromide (MTT) and dimethylsulfoxide (DMSO) were from Sigma (St. Louis, MO, USA); TRIzol and Fluo-3 AM were from Invitrogen Corp. (Carlsbad, CA, USA); and the Annexin V-fluorescein isothiocyanate (FITC) apoptosis detection kit and Hoechst 33258 were obtained from Key-Gen Biotech Co. Ltd. (Nanjing, China). Takara Taq ${ }^{\mathrm{TM}}$ and the PrimeScript ${ }^{\circledR}$ RT reagent kit (Perfect Real-Time) were purchased from Takara Biotech Co., Ltd. (Dalian, China); rabbit anti-Bax, rabbit anticaspase-12, rabbit anti-caspase-9, mouse anti-Bcl-2, mouse anti-cytochrome $c$ and mouse anti-caspase-3 antibodies and SuperSignal-enhanced chemiluminescent (ECL) substrate were from Millipore Co. (Billerica, MA,USA). The goat anti-GRP78, goat anti-GRP94, mouse anti-PERK, mouse anti-phosphoPERK (p-PERK) and mouse anti-phosphorylated-eukaryotic translation initiation factor $2 \alpha$ (p-eIF $2 \alpha)$ antibodies were from Santa Cruz Biotechnology, Inc. (Santa Cruz, CA, USA); goat anti-CHOP, mouse anti-poly(ADP-ribose) polymerase (PARP), rabbit anti-eIF2 $\alpha$, rabbit anti-ATF6 and rabbit anti- $\beta$-actin antibodies were obtained from Cell Signaling Technology (Danvers, MA, USA).

Cell culture and exposure to picosecond pulsed electric field (psPEF). The HeLa human cervical carcimona cells were a gift from the Institute of Ultrasound Engineering in Medicine of Chongqing Medical University. The cells were maintained in RPMI-1640 supplemented with $10 \%$ fetal bovine serum (FBS), $100 \mathrm{U} / \mathrm{ml}$ penicillin and $100 \mu \mathrm{g} / \mathrm{ml}$ streptomycin and incubated at $37^{\circ} \mathrm{C}$ in a humidified atmosphere $5 \% \mathrm{CO}_{2}$. When the cells grew to $\sim 80 \%$ confluence, they were subcultured or treated with psPEF. In the following experiments, cells loaded into cuvettes and merely placed into the circuit without being pulsed were used as the normal controls. A total amount of $100 \mu \mathrm{l}$ of cell suspension was exposed to 2,000 pulses for 800 psec with various electric field amplitudes.

Cell viability assay. Cell viability was evaluated by the MTT reduction assay. After treatment with various amplitudes of psPEF, HeLa cells were seeded at a density of $5 \times 10^{3}$ cells/ well in 96-well microtiter plates and routinely cultured for 12 and $24 \mathrm{~h}$ and then incubated with MTT $(5 \mathrm{mg} / \mathrm{ml})$ in culture medium for $3 \mathrm{~h}$ at $37^{\circ} \mathrm{C}$. Subsequently, the medium was discarded and formazan blue, which formed in the cells, was dissolved in $100 \mu \mathrm{l}$ of DMSO. The absorbance was measured at $490 \mathrm{~nm}$ using a Sunrise Remote Microplate Reader (Grodlg, Austria) and then normalized to the value of the control (untreated cells).

Apoptosis analysis with flow cytometer. After treatment with pulses, HeLa cells were grown in $25 \mathrm{~cm}^{2}$ culture flasks for $12 \mathrm{~h}$. Cells were trypsinized, centrifuged, washed in PBS and then double-stained by using an Annexin V-FITC apoptosis detection kit according to the manufacturer's instructions. Samples were incubated at room temperature for $15 \mathrm{~min}$ in the dark with Annexin V and PI. The fluorescence in the cells was quantitatively analyzed at an emission wavelength of $530 \mathrm{~nm}$ and an excitation wavelength of $480 \mathrm{~nm}$ using a Vantage SE flow cytometer with a fluorescence activated cell sorting (FACS) system (Becton-Dickinson, San Jose, CA, USA).

Flow cytometric assessment of cell cycle. HeLa cells were harvested and fixed with ice-cold alcohol (75\%) for over a day and a night, following treatment with pulses and growth in $25 \mathrm{~cm}^{2}$ culture flasks for $12 \mathrm{~h}$. After being washed twice, the cells were incubated with PBS (pH 7.4) containing RNase $(5 \mathrm{U})$ and PI $(50 \mu \mathrm{g} / \mathrm{ml})$ for $15 \mathrm{~min}$ at $37^{\circ} \mathrm{C}$. Flow cytometry was performed using a FACS vantage SE flow cytometer.

Hoechst staining. Morphological changes occurring during apoptosis were detected by fluorescence microscopy after staining with $1 \mu \mathrm{g} / \mathrm{ml}$ Hoechst 33258 for $30 \mathrm{~min}$ at $37^{\circ} \mathrm{C}$ in the dark. More than 300 cells were counted for each well by three independent experiments. 
Laser scanning confocal microscopy (LSCM) evaluation of intracellular $\mathrm{Ca}^{2+}$ levels. The HeLa cells were treated with psPEF and then seeded into 6-well plates for $12 \mathrm{~h}$. After incubation, they were washed and loaded with $0.5 \mu \mathrm{M}$ of Fluo-3-AM for $1 \mathrm{~h}$ at $37^{\circ} \mathrm{C}$ in the dark. The cells were washed twice with PBS and then subjected to LSCM (Leica TCS-SP2, Wetzlar, Germany) analysis by detecting the green fluorescence signals.

RNA extraction and gene expression analysis. Total RNA was extracted from the treated HeLa cells using TRIzol. Reverse transcription was performed in $20 \mu 1$ of reaction mixture containing $2 \mu \mathrm{g}$ of total RNA, $5 \mathrm{U}$ of AMV reverse transcriptase, 50 pmol of oligo(dT) primer, $40 \mathrm{nmol}$ of dNTP mixture, $40 \mathrm{U}$ of RNase inhibitor, $4 \mu \mathrm{l}$ of $5 \mathrm{X}$ RT buffer (Hangzhou Bioer Technology Co., Ltd, Hangzhou, China) at $42^{\circ} \mathrm{C}$ for $1 \mathrm{~h}$ and $95^{\circ} \mathrm{C}$ for $5 \mathrm{~min}$. Reverse transcription-polymerase chain reaction (RT-PCR) was used to examine the expression of caspase-12, -9 and -3. PCR amplification was performed in $20 \mu \mathrm{l}$ of PCR reaction mixture containing $1 \mu \mathrm{l}$ of the cDNA reaction mixture, $10 \mathrm{nmol}$ of the $\mathrm{dNTP}$ mixture, $10 \mathrm{pmol}$ of the upstream and downstream primers and $2 \mathrm{U}$ of rTaq polymerase. Real-time quantitative polymerase chain reaction was used to examine the expression of ER stress-associated genes, namely glucose-regulated protein-78 (GRP78), glucose-regulated protein-94 (GRP94) and CHOP. For determination, SYBRGreen detection was used and the values were normalized to those of $\beta$-actin.

Western blot analysis. After treatment with pulses and routine culture for $12 \mathrm{~h}$, the HeLa cells were washed with ice-cold PBS and lysed in RIPA lysis buffer (50 mM Tris with pH 7.4, $150 \mathrm{mM} \mathrm{NaCl}, 1 \%$ Triton $\mathrm{X}-100,1 \%$ sodium deoxycholate, $0.1 \%$ sodium dodecyl sulphate and $0.05 \mathrm{mM}$ EDTA) for $15 \mathrm{~min}$ on ice and the cell lysate was centrifuged at $12,000 \mathrm{x} g$ for $15 \mathrm{~min}$ at $4^{\circ} \mathrm{C}$. The supernatant was collected and the protein content of the extracted samples was measured using the bicinchoninic acid protein assay kit (Bio-Med, Beijing, China). All samples were stocked at $-80^{\circ} \mathrm{C}$ for further experiments. The levels of target proteins including $\mathrm{Bax}, \mathrm{Bcl}-2$, cytochrome $c$, procaspase-12, -9 and -3, PARP, GRP78, GRP94, CHOP, PERK, p-PERK, eIF $2 \alpha$, p-eIF $2 \alpha$ and activating transcription factor 6 (ATF6) were determined by western blot analysis using the respective antibodies stated above. Briefly, total cell lysate was boiled in $5 \mathrm{X}$ loading buffer $(125 \mathrm{mM}$ Tris- $\mathrm{HCl}, \mathrm{pH} 6.8,10 \%$ SDS, $8 \%$ dithiothreitol, $50 \%$ glycerol and $0.5 \%$ bromochlorophenol blue) for $10 \mathrm{~min}$. Equal amounts of protein $(60 \mu \mathrm{g})$ were subjected to $8-15 \%$ sodium dodecyl sulphate polyacrylamide gel electrophoresis (SDS-PAGE) and transferred onto polyvinylidene fluoride membranes. The membranes were blocked with 5\% non-fat milk in PBS with $0.1 \%$ Tween-20 (PBST) for $1 \mathrm{~h}$ and incubated with primary antibodies overnight at $4^{\circ} \mathrm{C}$. Antibodies were detected using HRP-conjugated secondary antibody for $1 \mathrm{~h}$ at room temperature. Immunoreactive bands were visualized using enhanced chemiluminescence reagents (ECL) and densitometric analysis was performed with the use of a ChemiDoc image analyzer (Bio-Rad, Hercules, CA, USA).

Statistical analysis. The results were expressed as the means \pm SD of at least three independent experiments performed in triplicate. Comparisons between groups were performed using the Student's t-test and one-way analysis of variance (ANOVA). A value of $\mathrm{p}<0.05$ was considred to indicate a statistically significant difference.

\section{Results}

Effect of psPEF on HeLa cell viability. HeLa cell viability was examined by MTT assay following treatment with various amplitudes of psPEF at 12 and $24 \mathrm{~h}$. As shown in Fig. 1A, a gradual decrease in cell viability was observed with the increased amplitudes of psPEF. However, compared to the $12 \mathrm{~h}$ time-point, the percentage of cell viability was not significantly reduced at $24 \mathrm{~h}$ at the given amplitude of pulses. On the basis of these data, the experimenatl condition in which the HeLa cells were treated with the amplitude of 200, 400 and $600 \mathrm{kV} / \mathrm{cm}$ of psPEF and routinely cultured for $12 \mathrm{~h}$ after treatment was applied to the following experiments.

HeLa cells show characteristics of apoptosis with psPEF treatment. In order to assess whether the proliferation inhibition induced by psPEF in the HeLa cells was associated with apoptosis, Annexin V-FITC/PI fluorescence was measured by flow cytometric analysis. The appearance of the cells with a high Annexin signal and a low PI signal is characteristic of early apoptosis. The progression of apoptosis results in cells with a high Annexin signal and a high PI signal characteristic of late apoptosis. As presented in Fig. 1B, for the vehicle-treated control group, $4.49 \%$ cells were negative for PI and positive for Annexin V-FITC binding, which represents apoptotic cells. Following exposure to psPEF (200, 400 and $600 \mathrm{kV} / \mathrm{cm}$ ), the percentage of apoptotic cells increased to 9.7, 14.66 and $22.95 \%$, respectively. To examine the role of psPEF in HeLa cell cycle progression, the cell cycle distribution was assessed by monitoring the intensity of PI fluorescence. The results indicated that psPEF blocked cell cleavage at the $G_{2} / M$ phase of the cell cycle (Fig. 1C).

Following treatment with different amplitudes of psPEF and culture for $12 \mathrm{~h}$, typical apoptotic morphological changes in the HeLa cells were detected by Hoechst 33258 staining (Fig. 2A and B). Fig. 2B clearly shows that the quantity of positive cells increased significantly compared to the control group $(\mathrm{p}<0.05)$.

psPEF induces the activation of the ER stress pathway. It is well-established that there are three ER transmembrane proteins identified as sensors of ER stress. These include PERK, IRE1 and ATF6. They activate the unfolded protein response (UPR) under ER dysfunction. Phospho-PERK phosphorylates eIF2 $\alpha$, decreasing gene expression. The IRE1 and ATF6 pathways promote the expression of ER chaperones and the pro-apoptotic transcription factor, CHOP $(23,24)$. In the current study, GRP78, GRP94 and CHOP expression was evaluated by real-time PCR and western blot analysis. There was a significant increase in expression $12 \mathrm{~h}$ after the pulses, regardless of the level of gene or protein, compared with the control group (Figs. 3A and B and 4A). p-PERK, p-eIF2 $\alpha$ and ATF6 fragments increased during the early period ( $6 \mathrm{~h}$ after the pulses), whereas their normal forms were not altered (Fig. 3C).

Cytosolic $\mathrm{Ca}^{2+}$ levels in psPEF-treated HeLa cells. Increases in intracellular $\mathrm{Ca}^{2+}$ levels have been found in ER-stressed 
A

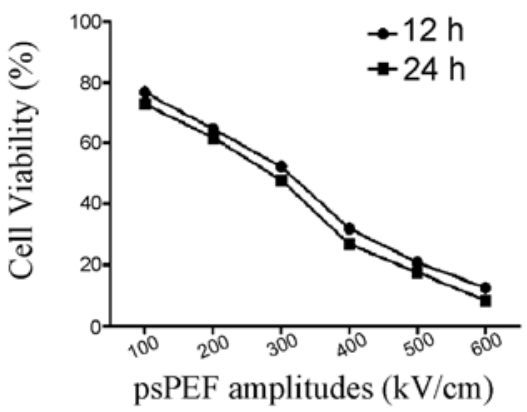

B
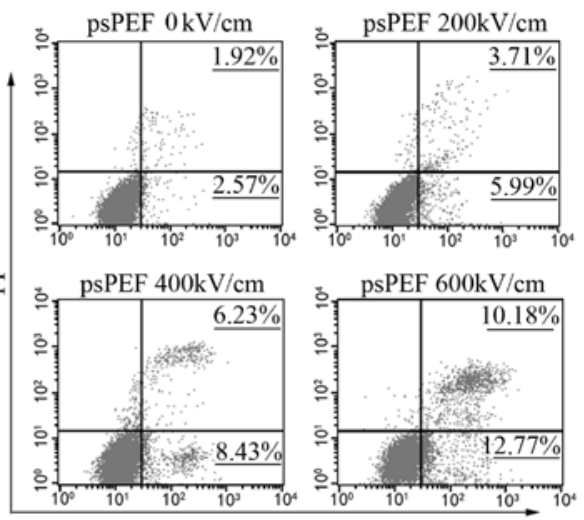

C
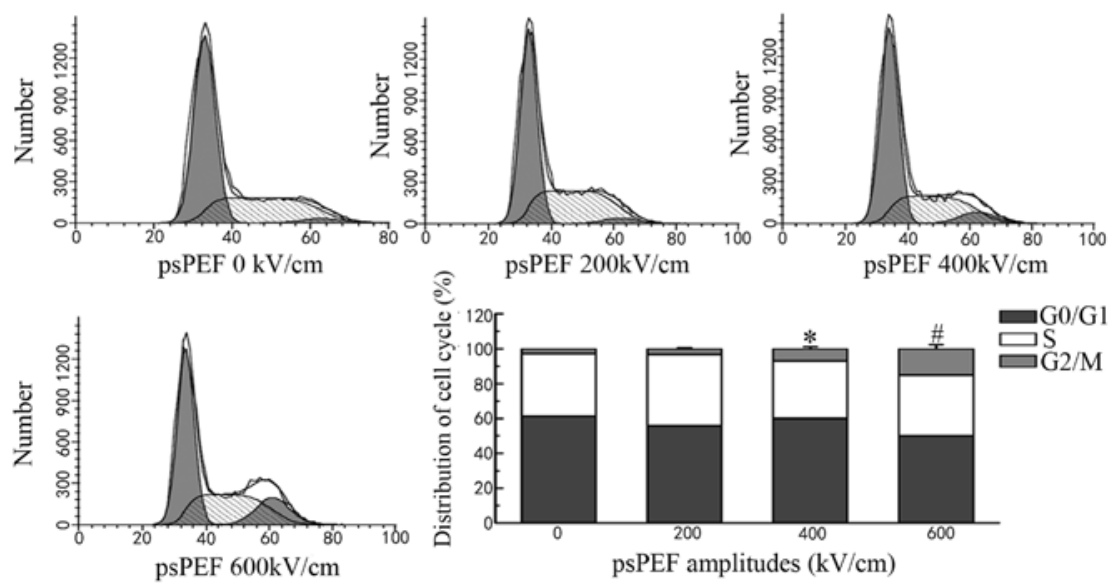

Figure 1. Effect of psPEF on cell viability measured by MTT assay and picosecond pulsed electric field (psPEF)-induced apoptosis in HeLa cells. (A) HeLa cells were treated with psPEF (100-600 kV/cm), with the number of 2,000 pulses for $800 \mathrm{psec}$. After treatment, cells were routinely cultured for 12 or $24 \mathrm{~h}$. Cell viability was determined by MTT analysis as described in Materials and methods. (B) Cells were treated, cultured for $12 \mathrm{~h}$, harvested and labeled with a combination of Annexin V-FITC and PI and then analyzed by flow cytometry. (C) Cells were treated, cultured for $12 \mathrm{~h}$, harvested and labeled with PI. The cell cycle distribution was analyzed by flow cytometry. ${ }^{*} \mathrm{p}<0.05,{ }^{\#} \mathrm{p}<0.01$ indicate a statistically significant difference compared with the vehicle-treated control group.
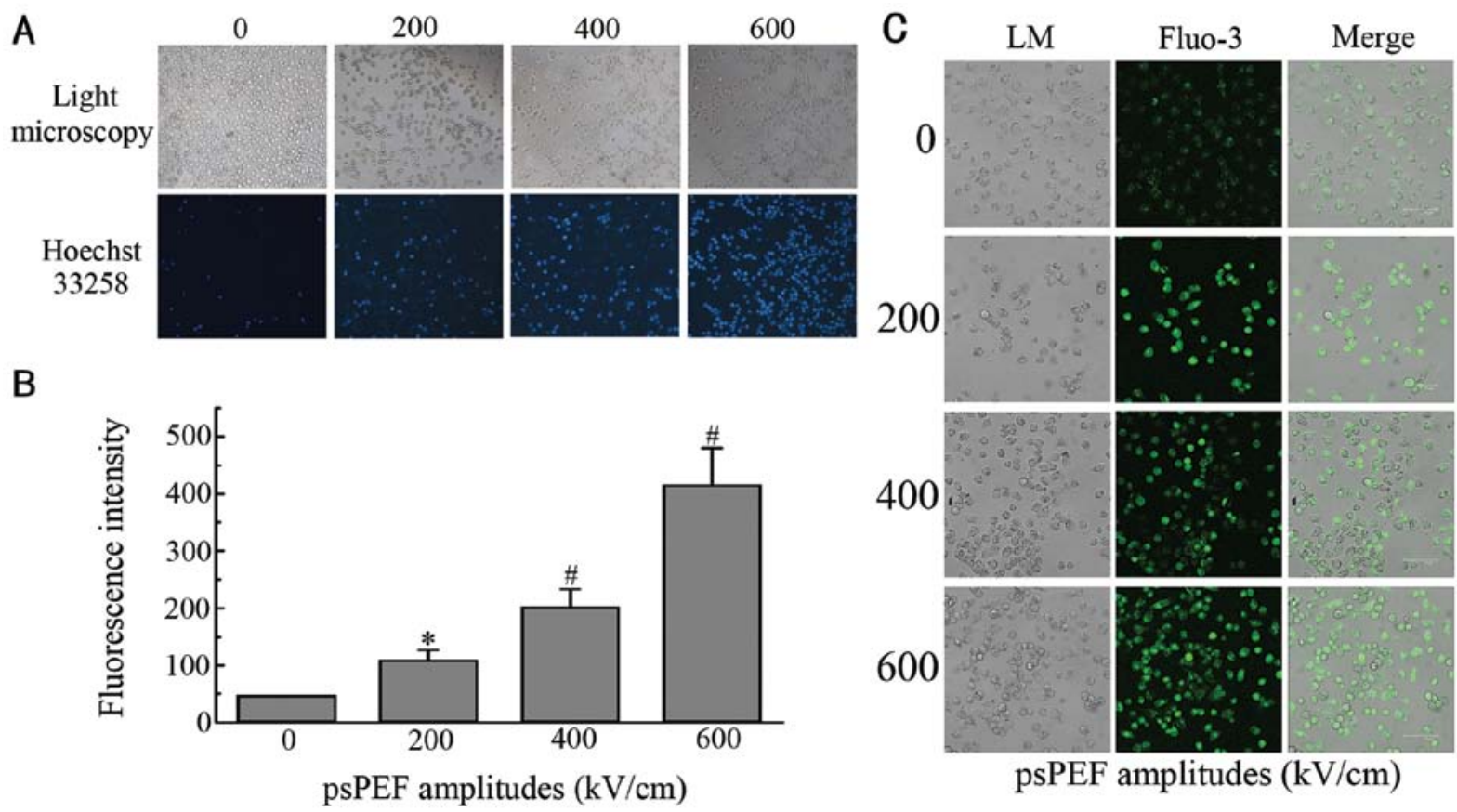

Figure 2. Morphological changes and increase in intracellular $\mathrm{Ca}^{2+}$ levels induced by psPEF. (A and B) Apoptosis was illustrated by Hoechst 33258 staining for morphological analysis. HeLa cells were treated, seeded into 96 -well culture plates for $12 \mathrm{~h}$ and then visualized by fluorescence microscopy (x10). $\mathrm{p}<0.05$, ${ }^{\#} \mathrm{p}<0.01$ indicate a statistically significant difference compared with the vehicle-treated control group. (C) Cells were treated with various amplitudes of psPEF and cultured for $12 \mathrm{~h}$. Levels of intracellular $\mathrm{Ca}^{2+}$ in HeLa cells were measured by the Fluo-3-AM dye using laser scanning confocal microscope (LSCM). Each value is the mean $\pm \mathrm{SD}$ of three determinations. 
A

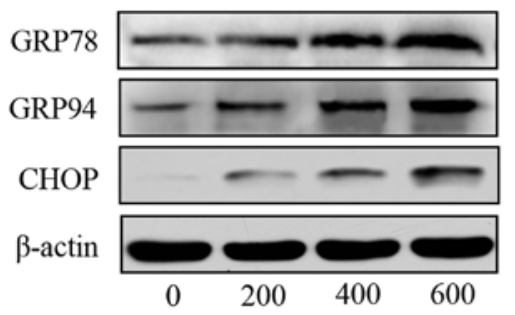

B

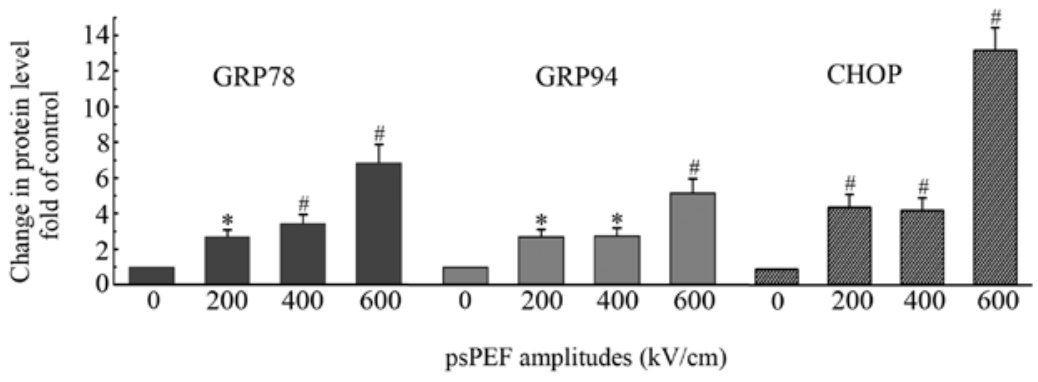

Figure 3. Effect of psPEF on the endoplasmic reticulum stress-related pathway. HeLa cells were pre-treated with various amplitudes of psPEF (200, 400 and $600 \mathrm{kV} / \mathrm{cm}$ ) and cultured for $12 \mathrm{~h}$ (A and B) or $6 \mathrm{~h}(\mathrm{C})$. Subsequently, the proteins were extracted. (A and B) Western blot analysis of the ER stress-related chaperones, GRP78 and GRP94, and the pro-apoptotic transcription factor, CHOP. (C) Western blot analysis of the ER stress sensors, PERK, p-PERK, eIF2 $\alpha$, p-eIF $2 \alpha$ and the ATF6 fragment (ATF6 f). ${ }^{*}$ p $<0.05,{ }^{*}$ p $<0.01$ indicate a statistically significant difference compared with the vehicle-treated control group.

cells (25). As indicated above, the apoptosis of HeLa cells induced by psPEF also involved ER stress; therefore, $\mathrm{Ca}^{2+}$ levels were measured. Cells were loaded with the calcium probe, Fluo-3-AM, and subsequently examined by immunofluorescence using confocal microscopy. Fig. $2 \mathrm{C}$ shows the fluorescence images of the control and treated groups $12 \mathrm{~h}$ after the pulses. The green fluorescence intensity increased after the pulses, which indicated the elevation of $\mathrm{Ca}^{2+}$ concentrations.

Effect of psPEF on the release of cytochrome $c$ and the activation of proteins from the Bcl-2 family. The development of apoptosis has been shown to be associated with an increase in cytosolic $\mathrm{Ca}^{2+}$ levels, which subsequently leads to mitochondrial depolarization and initiates a cell death cascade (26). The depolarization of the mitochondrial membrane induces the release of cytochrome $c$ into the cytosol, which is a prominent downstream manifestation of the evolution of apoptotic cell death (27). In our study, treatment with psPEF resulted in an increase in cytosolic cytochrome $c$ in a dose-dependent manner in the HeLa cells (Fig. 4B and C).

The Bcl-2 family, and in particular, the ratio of Bax (proapoptotic member) to Bcl-2 (anti-apoptotic member) is critical for regulating cell death. The balance between Bax and $\mathrm{Bcl}-2$ decides the destiny of cells (28). In our study, western blot analysis revealed that the expression of Bax was upregulated. By contrast, the expression of Bcl-2 was significantly downregulated (Fig. 4B and C).

Caspase-dependent pathway is activated by psPEF treatment. Caspases, a conserved enzymatic family, serve as the executioners of apoptosis. In response to apoptotic stimuli, they become activated (29). RT-PCR analysis demonstrated the psPEF-induced activation of caspase-12, -9 and -3 (Fig. 5A
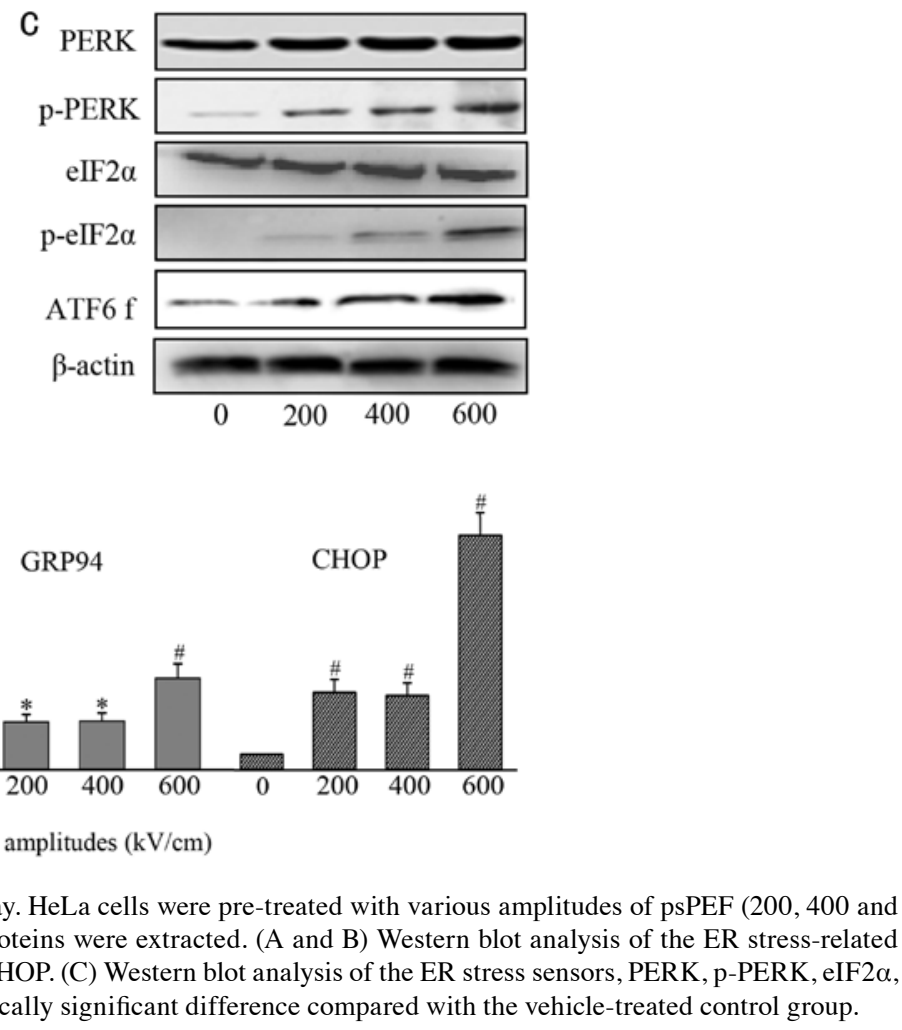

and B). Western blot analysis showed the downregulation of pro-caspase-12, -9 and -3 (Fig. 5C and D). To further identify the activation of the caspase cascade, PARP (116 kDa), one of the caspase downstream effectors, was examined by western blot analysis. In Fig. 5C and D, we show that the cleaved fragment of PARP (89 kDa) was increased.

\section{Discussion}

The discovery of a safe, effective and non-invasive treatment with preserved fertility for patients is becoming the most promising research direction. PEF is a new biomedical engineering technique which can be used as electrochemotherapy, tumor ablation and intracellular electromanipulation. In previous studies, the effectiveness of msPEF, $\mu \mathrm{SPEF}$ or nsPEF has been well proven. However, the application of msPEF, $\mu \mathrm{SPEF}$ or nsPEF requires the use of an invasive or minimally invasive needle or plate electrodes, to guide the puncture of tumor tissue, which, to a certain extent, limits the clinical application of this method. psPEF has an ultra-broadband optical spectrum, with extended time and spatial resolution and low signal distortion. It can be transferred to target deep tissue non-invasively and precisely with wideband antennas $(30,31)$. These features make the implementation of non-invasive treatment possible.

msPEF and $\mu$ sPEF mainly target the outer membrane, with few effects on the cell nucleus, mitochondria, ER and other organelles; thus, it causes electroporation to the outer membrane. As the pulse duration decreases, plasma membrane electroporation decreases and the electroporation effect changes gradually from the outer membrane to the intracellular substructures. It has been demonstrated nsPEF-induced apoptosis is not dependent on plasma membrane electroporation (32). 


\section{A}

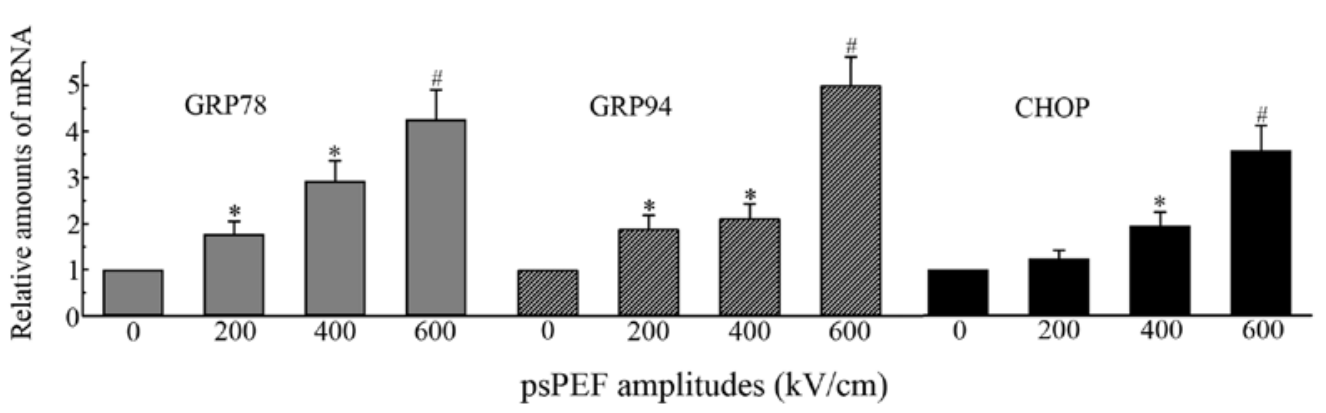

B
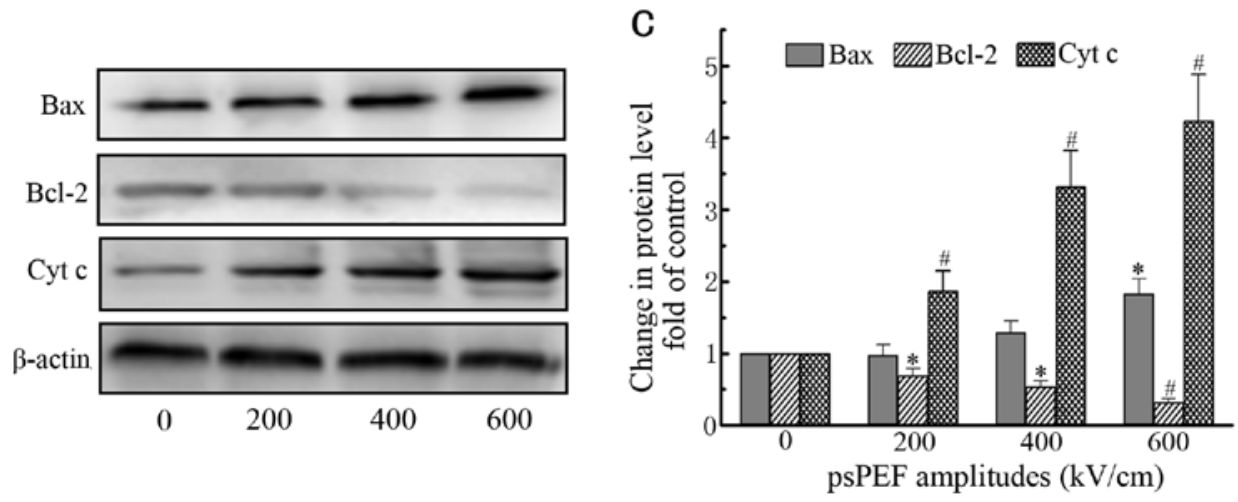

Figure 4. mRNA and protein alterations in HeLa cells upon psPEF treatment. HeLa cells were treated with various amplitudes of psPEF (200, 400 and $600 \mathrm{kV} / \mathrm{cm}$ ) and then cultured for $12 \mathrm{~h}$. (A) The mRNA levels of GRP78, GRP94 and CHOP was determined by real time RT-PCR as described in Materials and methods. The amount of mRNA was normalized to that of $\beta$-actin. (B and C) Western blot analysis was used to analyze the expression of Bax, Bcl-2 and cytochrome $c .{ }^{*} \mathrm{p}<0.05,{ }^{\#} \mathrm{p}<0.01$ indicate a statistically significant difference compared with the vehicle-treated control group. Cyt $\mathrm{c}$, cytochrome $c$.

A

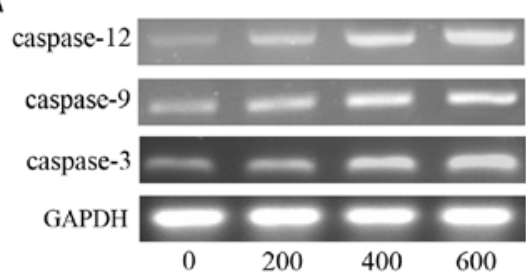

\section{C}

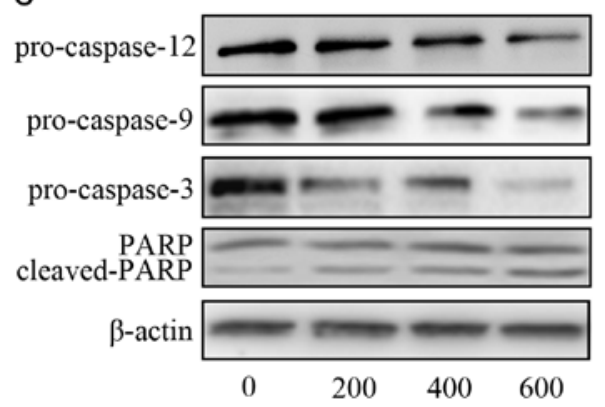

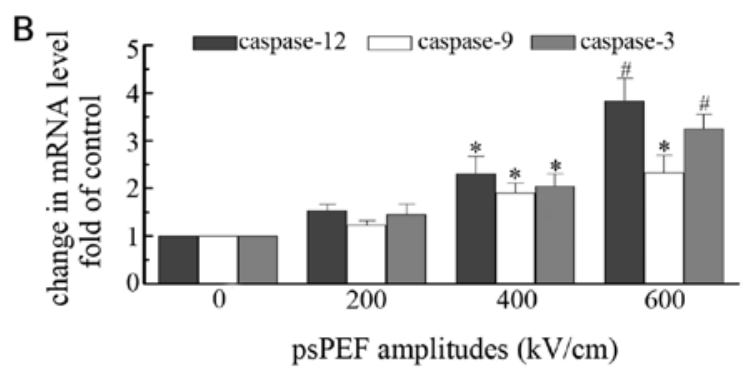

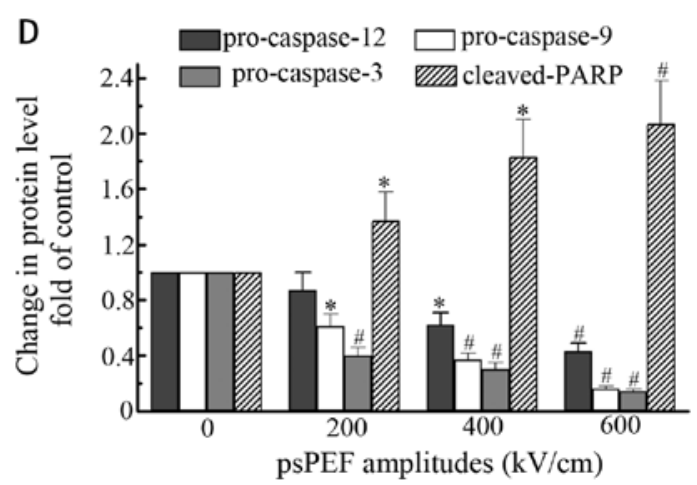

Figure 5. Effect of psPEF on the activation of caspases. HeLa cells were treated with various amplitudes of psPEF $(200,400$ and $600 \mathrm{kV} / \mathrm{cm})$ and then cultured for $12 \mathrm{~h}$. (A and B) RT-PCR analysis of the expression of caspase-12, -9 and -3. (C and D) Western blot analysis of the activation of caspases and their downstream effector, PARP. The expression of pro-caspase-12, -9 and -3 was decreased and the cleaved fragment of PARP $(89 \mathrm{kDa})$ was increased. ${ }^{*} \mathrm{p}<0.05,{ }^{\#} \mathrm{p}<0.01$ indicate a statistically significant difference compared with the vehicle-treated control group.

A previous study pointed out that ER is a subcellular compartment involved in the intrinsic apoptotic pathway (33). Under certain conditions, ER dysfunction leads to an accu- mulation of unfolded or misfolded proteins in the ER lumen and activates the compensatory mechanism, which has been referred to as ER stress response or unfolded protein 


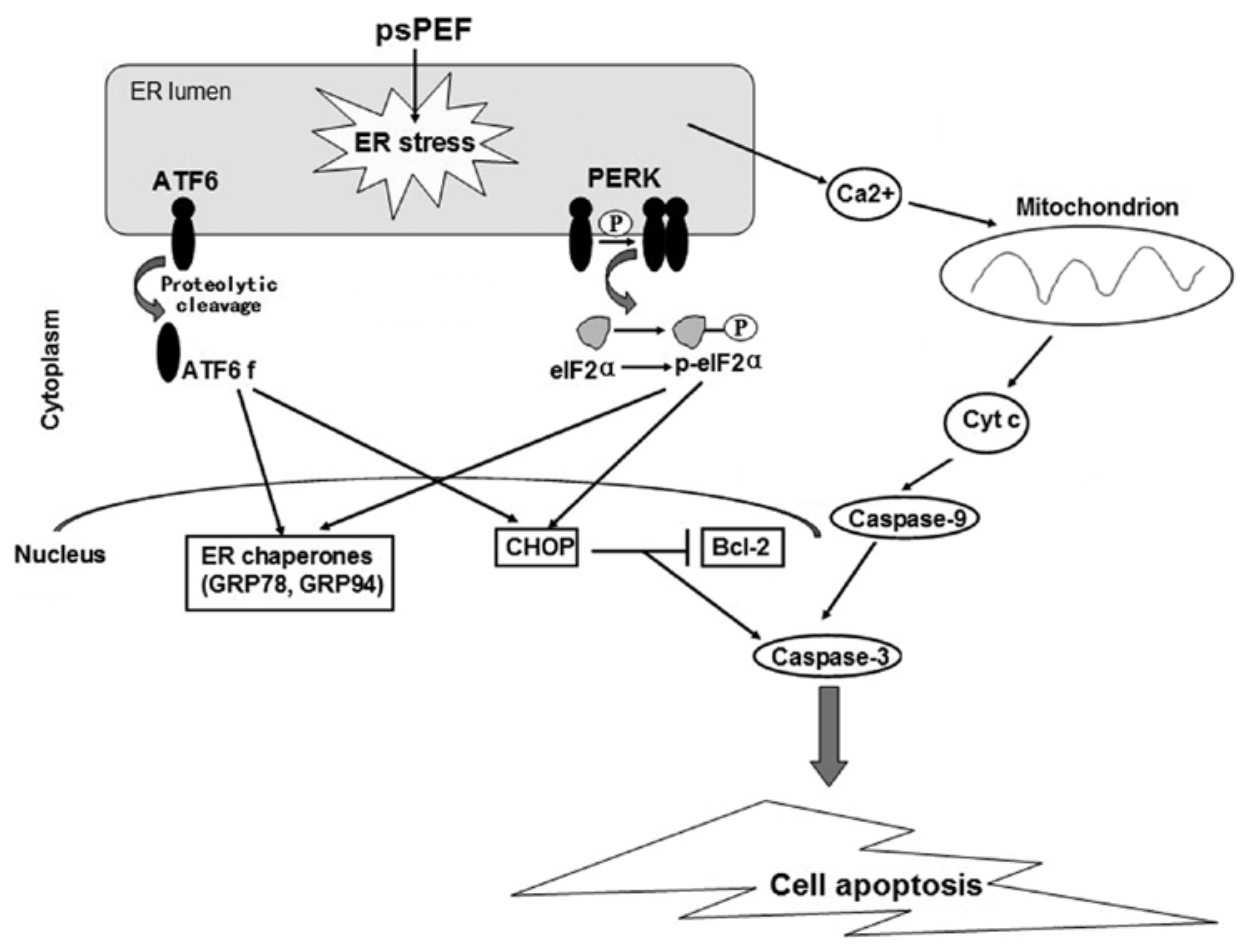

Figure 6. Signaling network: Mechanisms by which psPEF induces apoptosis, as proposed in this study. The schematic representation shows that psPEF induces apoptosis in HeLa cells by involving ER stress and the increase of cytosolic $\mathrm{Ca}^{2+}$ levels and then breaking the balance of Bax/Bcl-2, leading to the depolarization of the mitochondrial membrane, inducing the release of cytochrome $c$ and activating caspases.

response (34). The alterations of cellular protein expression related to psPEF stimulation can provide valuable information to point the occurrence of stress and also to help elucidate the mechanisms of action of pluses. Our study showed the upregulation of GRP78 and GRP94 (Fig. 3A and B). They are the chaperones of the heat shock protein family and responsible for the folding and maturation of non-glycosylated proteins. GRP78 is a key element in maintaining normal ER function and protecting the ER from dangerous stimulation. It controls the activation of transmembrane ER stress sensors through a binding-release mechanism and activates the downstream signaling pathways (35). In the present study, ER stress sensors were also assayed to validate the involvement of ER stress in the apoptotic process. Following psPEF exposure, PERK and eIF2 $\alpha$ were phosphorylated; however, the total protein level of PERK and eIF2 $\alpha$ was not affected, as shown in Fig. 3C. At the same time, ATF6 was cleaved to the activated form ATF6 fragmentation (Fig. 3C). These signaling transduction pathways are the adaptation responses to ER stress which can suppress the protein synthesis to relieve the burden of ER and increase the transcription of ER-associated chaperone genes (15). CHOP, a downstream pro-apoptotic component of the IRE1 $\alpha$, PERK and ATF6 stress responder pathways, is minimally expressed under physiological conditions; however, it is strongly induced in response to ER stress (36). The data presented in our study showed that CHOP expression was significantly upregulated. CHOP overexpression has been shown to lead to a decrease in the pro-survival protein, Bcl-2 (37), providing evidence that the pro-apoptotic functions of $\mathrm{CHOP}$ are associated with the mitochondrial-dependent mechanisms of cell death. Bax, a pro-apoptotic protein in the $\mathrm{Bcl}-2$ family, forms channels at the outer mitochondrial membrane to facilitate the release of cyto- chrome $c$. Under normal conditions, Bcl-2 forms heterodimers with the pro-apoptotic element, Bax. Under stress conditions, Bax enters the mitochondrial outer membrane, increasing membrane permeability and subsequently leading to cytochrome $c$ release by forming pores on the outer mitochondrial membrane (38). In the present study, psPEF treatment resulted in a significant increase in Bax expression and a decrease in Bcl-2 expression. Changes in the ratio of pro-apoptotic and anti-apoptotic Bcl-2 family proteins can activate downstream signaling, for example, caspase-3, eventually leading to apoptosis (39). Our data support this conclusion and are substantiated by observations of increased caspase 3 activity in HeLa cells treated with psPEF.

The regulation of intracellular calcium homeostasis is one of the main functions of ER. In our study, $\mathrm{Ca}^{2+}$ levels increased in the cytosol as shown in Fig. 2C, suggesting the involvement of ER stress in psPEF-treated HeLa cells. The abnormality of $\mathrm{Ca}^{2+}$ concentration in the ER can directly activate caspase-12 following cleavage by calpain-dependent apoptosis in the ER stress pathway (40). $\mathrm{Ca}^{2+}$ is released from the ER into the cytoplasm and the mitochondria (Fig. 6). The pathological overload of calcium in the mitochondria triggers the opening of the mitochondrial permeability transition pore (mPTP), which leads to mitochondrial dysfunction, thus, resulting in the release of the mitochondrial apoptogenic factor, cytochrome $c$ (41). Therefore, as shown in our study, the expression of cytochrome $c$ was increased (Fig. 4B and C). Cytochrome $c$ is released from the mitochondrial intermembrane spaces to initiate the subsequent activation of caspase-9, further activating downstream caspase-3. They are the executioners of apoptosis. In this study, we detected the downregulation of pro-caspase- 9 and -3 by western blot analysis (Fig. 5C and D). 
The decreased intensity of the pro-enzymes reflected the emergence of the cleaved form. Caspase-3 has been demonstrated to cleave its substrate, PARP, inducing characteristic apoptotic changes, such as chromatin condensation and DNA chromatin fragmentation (42).

In this study, to our knowledge, we demonstrate for the first time, the effect of ps-PEF on ER stress. Our current findings may lead to the discovery of a novel, non-invasive treatment for tumors. An understanding of the mechanism of ps-PEFactivated HeLa cells death is a basic step in clinical therapeutic approaches. Additional functional studies to identify the specific targets of psPEF are undergoing.

\section{Acknowledgements}

We are grateful for the support from The National Nature Science Foundation of China (project no. 81172123) and the Health Bureau of Chongqing (project no. 2012-2-068).

\section{References}

1. Jemal A, Siegel R, Ward E, Hao Y, Xu J and Thun MJ: Cancer statistics, 2009. CA Cancer J Clin 59: 225-249, 2009.

2. Karimi Zarchi M, Mousavi A, Malekzadeh M, Dehghani A, Behnamfar Z and Godarzi A: Conservative treatment in young patients with cervical cancer: a review. Asian Pac J Cancer Prev 11: 589-594, 2010.

3. Okino M, Tomie H, Kanesada H, et al: Optimal electric conditions in electrical impulse chemotherapy. Jpn J Cancer Res 83: 1095-1101, 1992.

4. Weaver JC: Electroporation: a general phenomenon for manipulating cells and tissues. J Cell Biochem 51: 426-435, 1993.

5. Hofmann GA, Dev SB, Dimmer S, et al: Electroporation therapy: a new approach for the treatment of head and neck cancer. IEEE Trans Biomed Eng 46: 752-759, 1999.

6. Dev SB, Rabussay DP, Widera G, et al: Medical applications of electroporation. IEEE Trans Plasma Sci 28: 206-223, 2000.

7. Stacey M, Stickley J, Fox P, Statler V, Schoenbach K, Beebe SJ and Buescher S: Differential effects in cells exposed to ultrashort, high intensity electric fields: cell survival, DNA damage and cell cycle analysis. Mutat Res 542: 65-75, 2003.

8. Craviso GL, Chatterjee P, Maalouf G, et al: Nanosecond electric pulse-induced increase in intracellular calcium in adrenal chromaffin cells triggers calcium-dependent catecholamine release. IEEE Trans Dielect El In 16: 1294-1301, 2009.

9. Stacey M, Fox P, Buescher S and Kolb J: Nanosecond pulsed electric field induced cytoskeleton, nuclear membrane and telomere damage adversely impact cell survival. Bioelectrochemistry 82 131-134, 2011.

10. Thompson CB: Apoptosis in the pathogenesis and treatment of disease. Science 267: 1456-1462, 1995.

11. Thorburn A: Death receptor-induced cell killing. Cell Signal 16: 139-144, 2004.

12. Budihardjo I, Oliver H, Lutter M, Luo X and Wang X: Biochemical pathways of caspase activation during apoptosis. Annu Rev Cell Dev Biol 15: 269-290, 1999.

13. Li UX, Kim CN, Yang J, Jemmerson R and Wang X: Induction of apoptotic program in cell-free extracts: requirement for dATP and cytochrome c. Cell 86: 147-157, 1996.

14. Yokouchi M, Hiramatsu N, Hayakawa K, Kasai A, Takano Y, Yao J and Kitamura M: Atypical, bidirectional regulation of cadmiuminduced apoptosis via distinct signaling of unfolded protein response. Cell Death Differ 14: 1467-1474, 2007.

15. Boyce M and Yuan J: Cellular response to endoplasmic reticulum stress: a matter of life or death. Cell Death Differ 13: 363-373, 2006.

16. Yamaguchi $\mathrm{H}$ and Wang HG: CHOP is involved in endoplasmic reticulum stress-induced apoptosis by enhancing DR5 expression in human carcinoma cells. J Biol Chem 279: 45495-45502, 2004

17. Moenner M, Pluquet $\mathrm{O}$, Bouchecareilh $\mathrm{M}$ and Chevet E: Integrated endoplasmic reticulum stress responses in cancer. Cancer Res 67: 10631-10634, 2007.
18. Schroder M and Kaufman RJ: ER stress and the unfolded protein response. Mutat Res 569: 29-63, 2005.

19. Yao CG, Guo F, Wang J, Li CX, Wen YQ and Tang JY: Study of tumor cell mitochondrial apoptosis signaling pathway induced by nanosecond pulsed electric fields. Chin J Biomed Eng 29: 724-730, 2010.

20. Liu LJ, Zhao DY, Wang J, Yao CG, Sun CX and Tang JY: $\mathrm{Ca}^{2+}$ is an important mediator of nanosecond steep pulse-induced apoptosis in human ovarian cancer SKOV3 cells. J Southern Med Univ 31: 772-776, 2011 (In Chinese).

21. Tang JY, Wu XJ, Yao CG, et al: The effects of nanosecond steep pulse on apoptosis and the concentration of intracellular calcium of human ovarian carcinoma cell Line SKOV3. Prog Obstet Gynecol 16: 827-831, 2007.

22. Hua YY, Wang XS, Zhang Y, Yao CG, Zhang XM and Xiong ZA: Intense picosecond pulsed electric fields induce apoptosis through a mitochondrial-mediated pathway in HeLa cells. Mol Med Rep 5: 981-987, 2012.

23. Hamanaka RB, Bennett BS, Cullinan SB and Diehl JA: PERK and GCN2 contribute to eIF2alpha phosphorylation and cell cycle arrest after activation of the unfolded protein response pathway. Mol Biol Cell 16: 5493-5501, 2005.

24. Davenport EL, Moore HE, Dunlop AS, Sharp SY, Workman P, Morgan GJ and Davies FE: Heat shock protein inhibition is associated with activation of the unfolded protein response pathway in myeloma plasma cells. Blood 110: 2641-2649, 2007.

25. Zhang D and Armstrong JS: Bax and the mitochondrial permeability transition cooperate in the release of cytochrome c during endoplasmic reticulum-stress-induced apoptosis. Cell Death Differ 14: 703-715, 2007.

26. Crow MT, Mani K, Nam YJ and Kitsis RN: The mitochondrial death pathway and cardiac myocyte apoptosis. Circ Res 95: 957-970, 2004.

27. Degli Esposti M and Dive C: Mitochondrial membrane permeabilisation by Bax/Bak. Biochem Biophys Res Commun 304: 455-461, 2003.

28. Zhou J, Zhang S, Ong CN and Shen HM: Critical role of proapoptotic Bcl-2 family members in andrographolide-induced apoptosis in human cancer cells. Biochem Pharmacol 72: $132-144,2006$.

29. Schlegel J, Peters I, Orrenius S, et al: CPP32/apopain is a key interleukin 1 beta converting enzyme-like protease involved in Fas-mediated apoptosis. J Biol Chem 271: 1841-1844, 1996.

30. Baum CE, Stone AP and Tyo JS (eds): Ultra-Wideband, ShortPulse Electromagnetics 8. Springer Press, New York, NY, 2007.

31. Bajracharya C, Shu X, Baum CE and Schoenbach KH: Target detection with impulse radiating antenna. IEEE Antennas Wireless Propag Lett 10: 496-499, 2011.

32. Beebe SJ, Fox PM, Rec LJ, Willis EL and Schoenbach KH: Nanosecond, high-intensity pulsed electric fields induce apoptosis in human cells. FASEB J 17: 1493-1495, 2003

33. Rao RV, Ellerby HM and Bredesen DE: Coupling endoplasmic reticulum stress to the cell death program. Cell Death Differ 11: 372-380, 2004.

34. Xu C, Bailly-Maitre B and Reed JC: Endoplasmic reticulum stress: cell life and death decision. J Clin Invest 115: 2656-2664, 2005.

35. Ni M and Lee AS: ER chaperones in mammalian development and human diseases. FEBS Lett 581: 3641-3651, 2007.

36. Oyadomari S and Mori M: Roles of CHOP/GADD153 in endoplasmic reticulum stress. Cell Death Differ 11: 381-389, 2004.

37. McCullough KD, Martindale JL, Klotz LO, Aw TY and Holbrook NJ: Gadd153 sensitizes cells to endoplasmic reticulum stress by down-regulating Bcl-2 and perturbing the cellular redox state. Mol Cell Biol 21: 1249-1259, 2001.

38. Yang JC and Cortopassi GA: Induction of the mitochondrial permeability transition causes release of the apoptogenic factor cytochrome c. Free Radic Biol Med 24: 624-631, 1998.

39. Oltvai ZN, Milliman CL and Korsmeyer SJ: Bcl-2 heterodimerizes in vivo with a conserved homolog, Bax, that accelerates programmed cell death. Cell 74: 609-619, 1993.

40. Nakagawa $T$ and Yuan J: Cross-talk between two cysteine protease families. Activation of caspase-12 by calpain in apoptosis. J Cell Biol 150: 887-894, 2000.

41. Boitier E, Rea R and Duchen MR: Mitochondria exert a negative feedback on the propagation of intracellular $\mathrm{Ca}^{2+}$ waves in rat cortical astrocytes. J Cell Biol 145: 795-808, 1999.

42. Nicholson DW and Thornberry NA: Apoptosis. Life and death decisions. Science 299: 214-215, 2003. 